\title{
Tine Tuberculin Skin Test
}

National Cancer Institute

\section{Source}

National Cancer Institute. Tine Tuberculin Skin Test. NCI Thesaurus. Code C85998.

A multiple puncture tuberculin skin test in which tuberculin antigen (either purified protein derivative or old) is pushed into the skin via a device containing 4-6 needles that are coated in tuberculin antigen. 